\title{
Profile Interview: Dr. Sufia Dadabhai
}

"I believe that through high quality, collaborative research and training opportunities, we can create a world in which every person has the opportunity to live a bealthy, long life

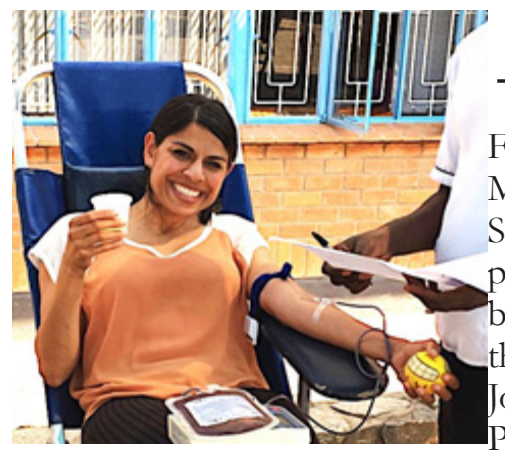
the cutting-edge HIV-related studies JHP is currentl undertaking, and specifically how the Project is positively impacting women's health and well-being in Malawi.

\section{FB: What is your personal and professional background?}

SD: My mum emigrated from Burma and my dad from India. They met in the US, and moved to California. So I was born and raised in California, on the West Coast of the United States. My parents have always been involved in the community; they taught us that if your neighbor and your neighbor's neighbor are doing well, then we are all doing better together. I have only one sister, but many cousins, aunts and uncles, and we were always together growing up; it was a warm and lively environment to be raised in. I attended boarding school at Phillips Academy Andover in Massachusetts, and returned to the West Coast to attend Stanford University where I studied Human Biology and Religious Studies.

My mother does a lot of international medical work - most recently she was here volunteering at Lions Eye Hospital. She's an ophthalmologist and was probably the first one to introduce me to global health issues, to help me see disparities in quality and access to care, and the importance of using all the skills we have to benefit the broader community.

I was raised by my grandmother mainly. She didn't have formal education the way we know it - but she was a powerful woman who had the respect of many and she was an excellent role model for me. I'm thankful for all the women in my life that set the stage for me to excel. They knew that circumstances for women in society are often more challenging than for men, but to put it simply, they didn't care and pushed on.

I had a chance to work in Cape Town for one year during University. I applied for a clinic-based internship but it turned out to be very public-health focused. That was a forkin-the-road moment for me; I chose public health instead of medicine and never looked back. The organisation's main goal was to reduce violence related to the ongoing HIV epidemic. There were a number of myths and misunderstandings about HIV in the community and it was driving fear and anxiety, leading to violence. That was my first introduction to on-theground field work, designing and delivering interventions, http://dx.doi.org/10.4314/mmj.v29i3.12 and measuring impact.

I attended Johns Hopkins for both my Master's and PhD I'm a trained epidemiologist; my focus is infectious diseases. My mentor and supervisor at Johns Hopkins is Dr. Taha Taha, who worked in Malawi for several years. I moved to Blantyre in October 2015 after being appointed to the JHP Field Director position.

FB: How do you feel about your career as an epidemiologist in infectious diseases?

SD: I have always had an interest in empowering people with education, technologies and tools to better themselves and to improve their chances at a healthy life. I could have done that in many different ways, through teaching or the arts or engineering, but you have to find what you're good at. My niche was research. I enjoy both the theoretical and applied aspects of epidemiology. I feel fortunate to work in a field that I love and am motivated both internally by my desire to do good work and by the incredible efforts of the people around me at JHP. Of course, there are days when you can't love everything about work, and that's when you need exercise, or reading or social engagement to help you re-energize, but I do love what I do and strongly believe that together, researchers, advocates, health care providers and policy makers can really raise the bar.

\section{FB: Tell us a brief history of the Johns Hopkins Research Project in Malawi}

SD: JHP was started in 1988 - next year will mark thirty years in Malawi. It started very small, with a few dedicated and interested scientists and physicians. This was just before the College started, but the relationship with people who would soon be the faculty and founders of COM was already there; the relationship with the Ministry was there. The initial studies looked at the basic epidemiology of HIV: just understanding how HIV gets transmitted, things that we take for granted now, such as which body fluids transmit HIV, but somebody had to figure that out. The initial focus was on mother to child transmission; that was the interest and passion of those starting the Organisation. JHP has expanded to include prevention and treatment research among adult men, non-pregnant women and adolescents. We've evolved and changed with the times based on what kind of research questions are relevant to Malawi and the region.

FB: How has your profession as an epidemiologist contributed to the work you do today?

SD: Public health is an interdisciplinary field and epidemiology Malawi Med J. 2017 Sep;29(3):278-281 
is one area within this diverse field. To me, I feel it's the core science of public health: it's the study of patterns of disease distribution and the causes of those patterns. It can be as simple as a food-borne outbreak: Was it the cauliflower or broccoli? Was it the chicken or the egg salad? Where is the source? Now we are asking really big questions around multilevel causes of disease and predicting epidemic patterns that we haven't even observed yet. One of the key elements of epidemiology is understanding study design and bias, and how to design and implement a study in a way that you'll actually be able to answer the question you've raised. Why is that important? Because resources are limited. So we have to use time, money and effort wisely. Putting effort into a study that's not going to yield the information you need to make good public health decisions is not a good use of resources. That's one reason I enjoy epidemiology - to really understand the best way to ask good questions and design good studies.

\section{FB: How did you feel when you were told to be the director of the JHP in Malawi?}

$S D$ : It was a mix of nerves and excitement. It's a very different position for me. I had never worked with a team this large before. We have almost 190 extremely hardworking and dedicated staff. So to be worthy of being their leader is something I really fight for every day. Of course, I was nervous about leaving a comfortable life and being far from friends and family. But the opportunity to have a positive impact on an already great organisation was extremely exciting.

FB: What comprises your responsibilities as the Director?

SD: I'd say I have four main responsibilities. One is to lead. That means I need to create an environment in which my staff can perform their work to the best of their abilities. They need to have space, supplies, training, adequate salaries to care for themselves, electricity, reagents, etc.; all those pieces need to be in place for them to succeed at the role that they've been asked to play at JHP.

I also help ensure we have enough resources, not just today or next month but also understanding the needs in the next one to three years - thinking the big picture and predicting changes. I work closely with our management team to best use the resources we all worked so hard to obtain.

I also feel really passionate about setting a positive tone at JHP, which is good for internal harmony and also external fostering collaborations. Having a positive, professional, pleasant work environment - that is important for the soul, partly because we all spend so much time at work. It starts with leadership to set that tone. It can be small things: keeping my office door open so staff feel welcome to drop by, which creates an opportunity to ask how their day is going or to brainstorm a new idea. So much of the work isn't done in meetings or calls but in informal one-on-one interactions; so, being present, showing up, being available, that's really important to me.

http://dx.doi.org/10.4314/mmj.v29i3.12
It's also important for me to make sure we're advancing the science. We are a research organisation and want to contribute to knowledge in a meaningful and substantive way. So, it's my responsibility to ensure we are disseminating study findings and knowing what's happening in the broader world of HIV research and to make sure my senior staff are also learning the most up-to-date information, so that we're putting our energy towards the most relevant questions.

\section{FB: What challenges do you encounter as a woman working in a field that is traditionally dominated by men? How do you overcome those challenges?}

$S D:$ I wish this didn't have to be a question but we'd be naïve to think it's not an important topic. I am honoured to be JHP's first female leader. So many staff are women and it's important for junior staff to see themselves reflected in the leadership of the Organisation. The challenge is that some people have misinformed expectations and assumptions about how females in leadership should or shouldn't behave. When I started this position, some were vocal to say, "Oh, we never thought we'd see the day with a woman as Field Director." But it's really just about who the best person is for the job at that time. My solution is to be unapologetic, keep my head up and keep doing the work. I think the hard work can speak for itself and that's what I reply on when facing sexism in society. You work hard, you show genuine interest, you excel. I have a lot of exciting responsibilities here, and that doesn't leave much time to worry about what others may or may not be saying. Yes, we need to be aware, but challenges can't rule our days. So I guess the trick is to be aware, ignore the noise and get the work done.

\section{FB: What important work is JHP currently undertaking in the HIV research in Malawi, and how is it contributing towards addressing the HIV problem in the country?}

$S D:$ There is quite a bit of diversity in the types of studies we do but broadly speaking, we are a clinical trials research team and we conduct HIV prevention and HIV treatment studies.

In terms of prevention, up until now, most tools we've had are not female-operated. Negotiating condoms, abstinence, knowing your partner's HIV status: these options are not available to all women. So we need to develop ways in which women can take charge of their own health to prevent HIV. We are studying three different and new interventions: one is the monthly dapivirine vaginal ring, which slowly releases prophylactic levels of an antiviral agent called dapivirine. Another one is an infusion study. HIV-uninfected women have been consented to participate in a study involving infusions of monoclonal anti-HIV antibodies - which were developed by a research lab in the US - for the prevention of HIV. It is very innovative and cutting-edge. What we learn from this study will move us to the next phase of HIV antibody research, eventually leading to a new prevention agent to help women (and men) protect themselves. There's also an upcoming injectable pre-exposure prophylaxis (PrEP) study, and the agent is called cabotegravir. We are comparing it to oral, daily Truvada, which is a known PrEP drug that's already licensed in other countries. We know a daily pill is not ideal for everyone; there is a risk of forgetting a dose or 
losing pills or even where to store the pill if you don't have much privacy at home. So injectable options may be best for some women. We're excited to be a part of these three studies and our sister site, UNC-Lilongwe, is conducting them as well.

We also have an interesting treatment agenda. For example, if someone has both malaria and HIV, what's the appropriate treatment dose for clearing plasmodium from the system? If a baby is infected with HIV and malnourished, will the baby metabolize ARTs in the same way as babies who are not malnourished? We are about to embark on a potentially game-changing study called A5349, and it's a TB treatment regimen-shortening study. Right now, the standard of care for TB treatment involves six months of multiple medications daily. If this study is successful, the duration could potentially go down to four months, which is massive savings in terms of adherence and total time and pill burden on an individual and the health care system.

We also do observational research among women living with HIV and their infants to track the impact of ARV exposure during conception and throughout pregnancy, during delivery and breast-feeding. We all know that ART is a life-saving tool for both prevention and treatment. As more people have access to ART, it's important to monitor how it impacts the mother's and baby's bodies as the baby is developing, based on the duration of exposure to ART.

We are part of a multi-site research network and some of the studies we are doing here are also happening in Boston, Seattle, Peru, India, Thailand, Uganda, Zambia, etc. Teamwork with these partner sites has been critically important.

FB: How do you see your work impacting positively on reproductive health in Malawi particularly in improving women's health and well-being?

$S D$ : I am proud to say that the research we have done has had a positive impact on both policy and practices in the area of prevention of mother-to-child transmission of HIV. For example, the PEPI Study, the Pre-Exposure Prophylaxis for Infants Study, actually helped mold the guidelines for duration of breastfeeding among HIV-infected women and their HIV-exposed infants. It's rewarding when our research can make interventions safer, more accessible and efficacious than before. Similarly, we participated in in HPTN 052, which was a landmark study to understand how immediate versus deferred ART can lead to not only better health for HIV-infected individuals but also nearly eliminate the risk of transmission to uninfected partners. That study really catapulted policy towards test and treat models for HIV, instead of waiting until the CD4+ cell counts have dropped below a certain threshold. That has had a big impact on women's health on a policy level.

Even on a daily basis, I feel we are impacting women's lives. The women that we recruit, consent and enroll into our studies become part of our team. We see some of them for more hours in a day than we see our own families! Some of them are in the clinics every month with a range of concerns and questions, and we become their standard of care provider even on issues that don't relate to the study. Sometimes, it's just a chat with someone who had a stressful day and the woman needs some counselling and motivation. Our participants are our partners in the work that we do, and they have the right to be in the study voluntarily and if they don't want to be in the study, that's also their choice. Respecting that choice is also empowering for women.

\section{FB: What can you say are the factors behind the success of Johns Hopkins Project?}

$S D$ : Two important factors are our reputation of conducting good quality research and our history of being the first HIV biomedical research institution in Malawi once news of HIV first broke. We have existed through several transitions in the Ministry and College of Medicine, and many changes in HIV in terms of access to treatment and paradigm shifts in prevention.

Our Community Engagement Department has also contributed to the longevity of JHP; they make sure our stakeholders are informed and are part of the research we do; that can be City Council, the Police Department, local NGOs, the STI clinic nurses, COM and Queens Leadership, etc. They all have a stake in the research we do. None of us can do the work alone and we rely heavily on mutual respect and sustained engagement with stakeholders to achieve our common goal.

When we interview new staff, there is always a question about teamwork. If somebody is not good with teamwork, they won't excel here at JHP. We rely a lot on communication between departments and have a team-based approach to problem-solving. Of course, sometimes, urgent decisions have to be made, but teamwork is a core factor for success.

Finally, I think it's the way we treat participants with respect and care, respecting the fact that they have busy, complex lives and they are volunteering their time to be with us. Sometimes they invite us to their churches to give talks or even to their weddings to help celebrate! These interpersonal relationships really matter.

So community engagement, teamwork, the way we treat people, commitment to quality and our longevity - these are all important for us.

\section{FB: How does your Project relate with its counterparts?}

$S D$ : We are proud to be one of several COM research affiliates along with Blantyre Malaria Project, Malaria Alert Centre, MEIRU, MLW, etc. There are always more ways to collaborate, to reach out and align our efforts. Time becomes a limiting factor but the desire and intention are there. We pick up the phone and call each other sometimes - How are you getting this done? Who's the best person to call for this task? Have you used this new lab equipment before? And so on. So we bounce ideas off of one another. We have a more 
formal partnership with some partners where we actually run tests for their studies, or we tap into expertise they have that we may not have yet. So I think the relationship is good and it can even be more fruitful and maximized. Time, money and effort are all limited resources. So, the best way to connect is probably to coordinate so that we don't duplicate. There is plenty of work to do and of course, there are different research agendas across the organisations but what matters is the mutual understanding and the mutual respect for each other's work and appreciation of what an affiliate brings to the table.

\section{FB: What kind of people does JHP recruit as employees?}

$S D$ : It really depends on the position that's available and the needs of the Organisation. Where is the gap in the team or how can one extra person help the whole team to shine and do its work better? In some cases, the best person is someone very seasoned in research. We also work with a number of people who are quite 'green' or new to research, but we see their passion for research and that research is part of their long-term career trajectory. For a number of our staff, they came to the interview and didn't know anything about clinical trials but they expressed passion to learn and be excellent, and came at the right place and the right time. So a number of pieces have to come together. We welcome people from a wide range of disciplines and skill levels.

\section{FB: What outstanding life experiences or achievements} are you proudest of?
$S D$ : That's a big question! Probably this position that I have right now. Serving the team here has been a huge source of professional and personal joy for me. Again, I think the work that we do is good for the community, good for Malawi, and good for global health. I haven't gotten here alone, certainly; I mentioned a number of role models - my parents, grandparents and sister - who have always applauded my successes but also propelled me to do better each day I walk through these doors. This work is not easy; it takes a lot of time to do it right and can be exhausting at times. But you do it because you love it.

\section{FB: Lastly, what is your vision for JHP?}

$S D$ : I value every life equally and that's what keeps me motivated. That's really important in a world full of disparities and differences in access to resources, people born into different geographies and different family dynamics, different access to education, etc. I think it's critically important to value every life equally and that relates to the vision I have for JHP. I believe that through high quality, collaborative research and training opportunities, we can create a world in which every person has the opportunity to live a healthy, long life. We can't do it alone but I think that's our piece of the puzzle, that's what epidemiology and JHP can bring to the table. Long after I've left JHP, I will ask myself, "Did we have some real impact?" I hope the answer is yes, and it will be because through research, we made a change in population health, in someone's life and opportunities that person has to shine. 